\title{
Analysis of thermo-physical properties of materials suitable for thermal stabilization of superconducting tapes for high- voltage superconducting fault current limiters
}

\author{
Marcela Pekarčíková ${ }^{1}$ (i) • Marián Drienovský ${ }^{1}$ (D) Jozef Krajčovičc ${ }^{1} \cdot$ Jozef Mišík $^{1} \cdot$ Eva Cuninková $^{1}$ (D) \\ Tomáš Húlan ${ }^{2} \cdot$ Ondrej Bošák ${ }^{1}$ (1) $\cdot$ Michal Vojenčiak $^{3}$
}

Received: 11 October 2018/Accepted: 27 April 2019/Published online: 9 May 2019

(c) The Author(s) 2019

\begin{abstract}
High-temperature superconducting coated conductors (CC) are attractive materials for high-voltage resistive fault current limiters. Commercially produced CC tapes cannot withstand electric fields over $100 \mathrm{~V} \mathrm{~m}^{-1}$, and therefore, they have to be modified by addition of thermal stabilization layer. We investigated several composite systems suitable for such thermal stabilization. As a matrix of composites, Stycast resins were used, which contain various contents of powder particles from $\mathrm{SiC}, \mathrm{SiO}_{2}, \mathrm{PbTiO}_{3}, \mathrm{ZrW}_{2} \mathrm{O}_{8}$, or synthetic diamond. The thermo-physical properties such as thermal expansion, heat capacity, thermal diffusivity and direct-current electrical conductivity were measured because they are influenced by filler content in the composite. The possible highest amount of the powder can slightly increase the thermal conductivity and decrease the thermal expansion of the system to an acceptable value needed for the coating of CCs. A side effect is simultaneous drop of heat capacity; however, its value stays still high enough for the purpose of heat sinking. Overall, the best results were achieved in system with $20 \mathrm{vol} \%$ of SiC filler in Stycast 2850FT + Catalyst 23LV resin matrix. There the contribution of the semiconducting $\mathrm{SiC}$ addition to the electrical conductivity of composite was negligible.
\end{abstract}

Keywords Epoxy-filler composite $\cdot$ Thermal stabilization $\cdot$ Coated conductor $\cdot$ Superconducting fault current limiter

\section{Introduction}

High-temperature superconducting (HTS) materials transport electric current without resistance. This peculiar property is, however, limited by the level of electric current, magnetic field and temperature because the superconductor loses its superconductivity due to exceeding their critical values. A transition from the superconducting to the resistive state is very fast (few milliseconds), and this

Marián Drienovský

marian.drienovsky@stuba.sk

1 Faculty of Materials Science and Technology in Trnava, Slovak University of Technology in Bratislava, Jána Bottu 25, 91724 Trnava, Slovakia

2 Faculty of Natural Sciences, Constantine the Philosopher University in Nitra, Tr. A. Hlinku 1, 94974 Nitra, Slovakia

3 Institute of Electrical Engineering, Slovak Academy of Science, Dúbravska cesta 9, 84104 Bratislava, Slovakia phenomenon makes the REBCO (RE-rare-earth element, $\mathrm{B}$-barium, C-copper, O-oxygen) superconductor as attractive material for superconducting fault current limiters (SCFCL) [1]. The resistive-type SCFCL works on a simple principle. The impedance of the SCFCL is very small when the grid works in normal conditions, because the normal current stays below the critical current, $I_{\mathrm{c}}$. During a fault, the current exceeds $I_{\mathrm{c}}$ value and consequently the resistance increases-the device switches to high impedance, and the current is limited [2]. The length of HTS-coated conductor (CC) tape needed in resistive SCFCL is proportional to the electric field, $E_{\max }$, which the tape is able to withstand after quenching to a non-superconducting (resistive) state. The SCFCLs designed with today's commercially available CCs can be applied for electric fields up to $50 \mathrm{~V} \mathrm{~m}^{-1}$. In case of a CC tape able to withstand $E_{\max }=150 \mathrm{~V} \mathrm{~m}^{-1}$, the required length would be significantly reduced and save two-thirds of the expensive conductor. Such electric field increase, however, leads to quick overheating of a thin silver stabilization layer in the 
CC. Its temperature rises during a very short time (several seconds) to more than $250{ }^{\circ} \mathrm{C}$ which can permanently degrade adjacent superconductor and finally damage the whole device $[1,3]$. Therefore, a modification of commercially produced CCs is required. Several concepts are developed in frame of Horizon 2020 project-FastGrid [4] - and one of them is based on thermal stabilization of the tape by coating the $\mathrm{CC}$ with a material possessing a high heat capacity $\left(c_{\mathrm{p}}\right)$ as depicted in Fig. 1.

The thermal stabilization from a polymeric material like resin is easy to prepare by coating on the top of the CC tape with relatively low costs. Certainly, this coating must meet expectations in several important material properties like high heat capacity, high electrical resistivity, good thermal conductivity and appropriate thermal expansion which should be similar to the thermal expansion of the $\mathrm{CC}$ substrate (usually Hastelloy $\mathrm{C} 276^{\circledR}$ ) to prevent the delamination of the coating from the $\mathrm{CC}$ tape. Besides this, the coated layer should preserve the flexibility of the CC tape and must be suitable for cryogenic temperatures.

Stycast epoxy resins have been used for applications in cryogenic temperature range, for example as an encapsulating material for HTS coils to prevent movement of the tapes and distribute loads evenly [5-7]. Besides this, the resins can withstand elevated temperatures above $100{ }^{\circ} \mathrm{C}$ and in the form of coated layer with thickness up to $400 \mu \mathrm{m}$ remain flexible. The thermal expansion of the resins is in general much larger than the expansion of the CC tapes. This mismatch has to be reduced to possible minimum through the addition of filler with low thermal expansion. The coefficients of thermal expansion (CTE) of materials like $\mathrm{SiC}, \mathrm{SiO}_{2}, \mathrm{PbTiO}_{3}, \mathrm{ZrW}_{2} \mathrm{O}_{8}$ or diamond have low or even negative value (Table 1). According to several papers reported in [8-12], their addition in the form of powder to various materials had successfully reduced the thermal expansion of a final composite. This concept has also another advantage; the use of an insulating binder keeps unreduced the conductor resistivity in resistive, nonsuperconducting state.
In this work, the thermo-physical properties of several systems resin-powder filler were measured in order to evaluate their suitability as thermal stabilization of the $\mathrm{CC}$ tapes for SCFCLs.

\section{Experimental}

Commercially available two component resins Stycast transparent (Stycast 1266 A/B) and Stycast black (Stycast $2850 \mathrm{FT}$ ) hardened using hardener Catalyst $23 \mathrm{LV}$ were used for the preparation of samples. A low value of viscosity, good adhesion and thermal shock properties were taken into account by their selection. $\mathrm{SiC}, \mathrm{SiO}_{2}, \mathrm{PbTiO}_{3}$, $\mathrm{ZrW}_{2} \mathrm{O}_{8}$ and synthetic diamond powders were added as filler to the resin, using different mixing ratios listed in Table 2. This table contains also data about particle size, which was different for each powder. Figure 2 shows images of used pure powders taken by scanning electron microscope (SEM).

A specified quantity of the epoxy resin and catalyst was mixed thoroughly before the powder was added. Then, the mixture was mechanically stirred for $10 \mathrm{~min}$ at room temperature. The samples containing Stycast transparent and Stycast black were cured at room temperature for $16 \mathrm{~h}$ and $24 \mathrm{~h}$, respectively. In order to have stable samples for thermo-physical measurements (with closed polymerization process), they were additionally heated in convective oven to $200{ }^{\circ} \mathrm{C}$ with holding time of $2 \mathrm{~min}$ at this temperature.

The thermal expansion was measured on cylinder bars $(\phi 4.7 \mathrm{~mm} \times 12 \mathrm{~mm})$ using a Netzsch DIL 402C dilatometer in helium environment (gas flow $25 \mathrm{~mL} \mathrm{~min}{ }^{-1}$ ) with a heating rate of $3{ }^{\circ} \mathrm{C} \min ^{-1}$ over the temperature range from -140 to $200{ }^{\circ} \mathrm{C}$. Compressive force was $0.3 \mathrm{~N}$. The measurement of certified alumina standard (correction measurement) was done before each batch of samples to ensure the most accurate results of CTE. The CTE was determined from the slope of the plot between the thermal expansion and the temperature in two
Fig. 1 Concept of modified commercial CC tape by coating with high $c_{\mathrm{p}}$ layer for thermal stabilization of $\mathrm{CC}$ used in SCFCL

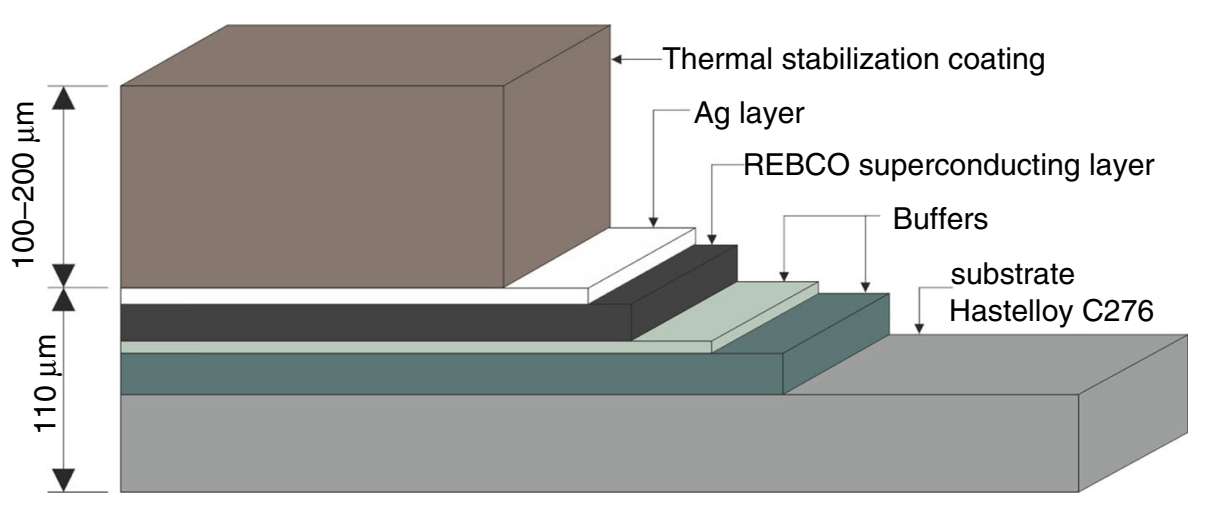


Table 1 Thermo-physical properties of filler materials at room temperature

\begin{tabular}{llllll}
\hline & $\mathrm{SiO}_{2}$ & $\mathrm{SiC}$ & Diamond & $\mathrm{PbTiO}_{3}$ & $\alpha-\mathrm{ZrW}_{2} \mathrm{O}_{8}$ \\
\hline Linear CTE$/ \mathrm{K}^{-1}$ & $0.5 \times 10^{-6}$ & $3.7 \times 10^{-6}$ & $0.9 \times 10^{-6}$ & $-1.99 \times 10^{-5}$ (average volumetric CTE) & $-8.7 \times 10^{-6}$ \\
Thermal conductivity/ $\mathrm{W} \mathrm{m}^{-1} \mathrm{~K}^{-1}$ & 1.3 & 270 & 2000 & 1.5 & 0.5 \\
References & {$[13]$} & {$[14]$} & {$[14]$} & {$[15,16]$} & {$[17]$} \\
\hline
\end{tabular}

Table 2 Investigated samples of Stycast transparent (ST) and Stycast black (SB) resins and composites prepared by adding various powder fillers into these resins

\begin{tabular}{lllc}
\hline Sample & Resin & Powder/particle size/ $\mu \mathrm{m}$ & vol\% of powder \\
\hline $\mathrm{ST}$ & Stycast $1266 \mathrm{~A} / \mathrm{B}$ & - & 0 \\
$\mathrm{ST}-\mathrm{SiC} 11$ & Stycast $1266 \mathrm{~A} / \mathrm{B}$ & $\mathrm{SiC} / 3-100$ & 11 \\
$\mathrm{ST}-\mathrm{SiC} 27$ & Stycast $1266 \mathrm{~A} / \mathrm{B}$ & $\mathrm{SiC} / 3-100$ & 27 \\
$\mathrm{ST}-\mathrm{SiC} 42$ & Stycast $1266 \mathrm{~A} / \mathrm{B}$ & $\mathrm{SiC} / 3-100$ & 42 \\
$\mathrm{ST}-\mathrm{dia} 40$ & Stycast $1266 \mathrm{~A} / \mathrm{B}$ & diamond/30-40 & 40 \\
$\mathrm{SB}+23 \mathrm{LV}$ & Stycast 2850FT + Catalyst 23LV & - & 0 \\
$\mathrm{SB}+23 \mathrm{LV}-\mathrm{SiC} 10$ & Stycast 2850FT + Catalyst 23LV & $\mathrm{SiC} / 3-100$ & 10 \\
$\mathrm{SB}+23 \mathrm{LV}-\mathrm{SiC} 20$ & Stycast 2850FT + Catalyst 23LV & $\mathrm{SiC}_{3}-100$ & 20 \\
$\mathrm{SB}+23 \mathrm{LV}-q u a 10$ & Stycast 2850FT + Catalyst 23LV & $\mathrm{SiO}_{2} / 1-10$ & 10 \\
$\mathrm{SB}+23 \mathrm{LV}-\mathrm{PTO} 12$ & Stycast 2850FT + Catalyst 23LV & $\mathrm{PbTiO}_{3} / 0.1-1$ & 12 \\
$\mathrm{SB}+23 \mathrm{LV}-\mathrm{PTO} 20$ & Stycast 2850FT + Catalyst 23LV & $\mathrm{PbTiO}_{3} / 0.1-1$ & 20 \\
$\mathrm{SB}+23 \mathrm{LV}-Z W O 10$ & Stycast 2850FT + Catalyst 23LV & $\mathrm{ZrW}_{2} \mathrm{O}_{8} / 1-50$ & 10 \\
$\mathrm{SB}+23 \mathrm{LV}-\mathrm{ZWO} 15$ & Stycast 2850FT + Catalyst 23LV & $\mathrm{ZrW}_{2} \mathrm{O}_{8} / 1-50$ & 15 \\
$\mathrm{SB}+23 \mathrm{LV}-\mathrm{ZWO} 20$ & Stycast 2850FT + Catalyst 23LV & $\mathrm{ZrW}_{2} \mathrm{O}_{8} / 1-50$ & 20 \\
\hline
\end{tabular}
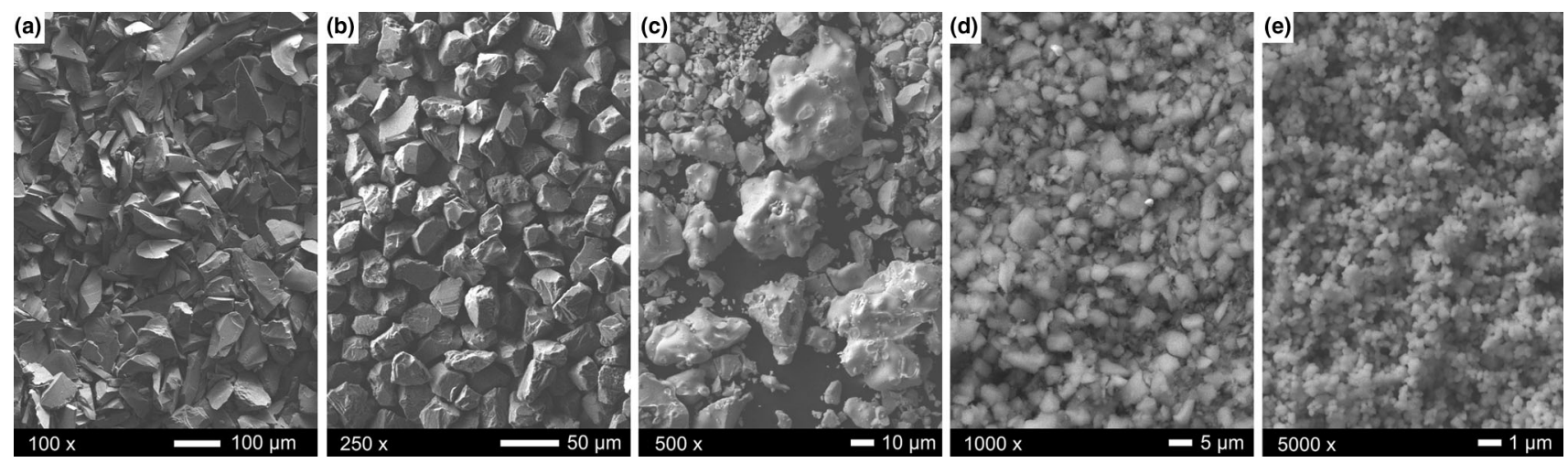

Fig. 2 SEM images of used powders for the preparation of composites: (a) $\mathrm{SiC}$, (b) synthetic diamond (c) $\mathrm{ZrW}_{2} \mathrm{O}_{8},(\mathbf{d}) \mathrm{SiO}_{2}$ and (e) $\mathrm{PbTiO}_{3}$

temperature ranges: from -140 to $20{ }^{\circ} \mathrm{C}$ and from 80 to $200{ }^{\circ} \mathrm{C}$, because of the presence of glass transition temperature, $T_{\mathrm{g}}$. The heat capacity of the samples was measured on a calibrated PerkinElmer Diamond differential scanning calorimeter (DSC) in $\mathrm{N}_{2}$ atmosphere (gas flow $20 \mathrm{~mL} \mathrm{~min}{ }^{-1}$ ) with a heating rate $10{ }^{\circ} \mathrm{C} \mathrm{min}^{-1}$ over the temperature range from -60 to $200{ }^{\circ} \mathrm{C}$. The correction measurements with empty DSC pan preceded the sample measurements. The sample's mass was varying about $35 \mathrm{mg}$. Each sample was placed in an aluminium DSC pan, and the empty pan was used as a reference material. All samples were measured three times because the first DSC curve was slightly different from second one. The second with the third measurement was almost identical, and these data were used for the determination of $T_{\mathrm{g}}$. The $c_{\mathrm{p}}$ values were calculated by a two-step method. A sapphire standard was occasionally measured to check instrument's calibration. Measurements of thermal diffusivity were carried out using NETZSCH LFA 427 laser flash analyser. The measuring temperatures were selected in the range between room temperature (RT) and $T_{\mathrm{g}}$. The samples with cylindrical shape of $12.4 \mathrm{~mm}$ in diameter and $2 \mathrm{~mm}$ in thickness were coated with graphite and measured at various temperatures below temperature of glass transition in static air 
atmosphere using a laser voltage of $480 \mathrm{~V}$ and pulse width of $0.4 \mathrm{~ms}$. The obtained values were refined by Cape Lehman + pulse correction model. The values of thermal conductivity were determined using the equation $\kappa=\rho \alpha c_{\mathrm{p}}$, where $\rho$ is density of the sample, $\alpha$ is the thermal diffusivity and $c_{\mathrm{p}}$ is the specific heat capacity. The density was determined by Archimedes method using Mettler Toledo precision laboratory scales. Demineralized water was used as immersion liquid. For determination of direct-current (DC) electrical conductivity, the electric current was measured at a constant voltage of $10 \mathrm{~V}(\mathrm{SB}+23 \mathrm{LV}$ samples with varied $\mathrm{SiC}$ content) as well as at $50 \mathrm{~V}$ and $100 \mathrm{~V}$ (SB + 23LV-SiC20 sample) using Novocontrol Concept 90 device in the temperature range from - 160 up to $200{ }^{\circ} \mathrm{C}$. The current was determined by picoammeter Keithley 6517B. The temperature was measured using a $\mathrm{S}$-type thermocouple with an accuracy of $\pm 1{ }^{\circ} \mathrm{C}$. The heating rate was $5^{\circ} \mathrm{C} \min ^{-1}$. Dimensions of samples were identical with samples for thermal diffusivity measurements.

\section{Results and discussion}

\section{Thermal expansion}

Thermal expansion is an important issue in modification of CC tapes due to coating since the delamination effects resulting from the too large difference between coated and coating materials are unacceptable. Figure 3 shows relative thermal expansions of prepared samples. Figure 3a depicts the systems with Stycast transparent resin. The second system with Stycast black is presented in two separated figures (Fig. 3b, c) because of better clarity. Finally, Fig. 3d gives overview of the best achieved results from each system in one plot compared with the thermal expansion of Hastelloy $\mathrm{C} 276^{\circledR}$. The thermal expansion of all Stycast resin-powder composites increases linearly with the temperature. The presence of glass transition was observed in temperature range approximately from 60 to $70{ }^{\circ} \mathrm{C}$ depending on particular sample, and after this area, the thermal expansion increases again linearly with the temperature, however, with higher slope. All composite samples showed a decrease in thermal expansion by adding powder in the resin in comparison with the pure resin samples.

The best results for Stycast transparent were achieved by mixing resin with the highest amount of $\mathrm{SiC}$ powder. The CTE at RT for this system was decreased more than two and half times (see Table 3 ). Since the ratio with 42 vol\% was a maximum which still allows a simple coating procedure of the $\mathrm{CC}$ tape with no stiff mixture, higher amounts of powder content in Stycast transparent were not tested.
Similar result was achieved also with diamond powder particularly in temperature range up to $T_{\mathrm{g}}$. However, its relatively high price in comparison with $\mathrm{SiC}$ and no significantly better effect on the CTE modification have played the main role by the decision to exclude this powder from the preparation of the next samples.

The CTE of pure Stycast black resin at RT is $38 \times 10^{-6} \mathrm{~K}^{-1}$, which is significantly lower in comparison with the first resin $\left(73 \times 10^{-6} \mathrm{~K}^{-1}\right)$. Therefore, overall better results were expected due to its mixing with the powder component. The best results for this system were achieved with $\mathrm{SiC}$ and $\mathrm{ZrW}_{2} \mathrm{O}_{8}$ powders as indicated Fig. 3. Both systems reduce the CTE at RT more than one and half times. From all investigated systems, the CTE value at RT $24 \times 10^{-6} \mathrm{~K}^{-1}$ is the closest achieved value to the CTE of Hastelloy $\mathrm{C} 276^{\circledR}$ usually used as substrate which defines the thermal expansion properties of $\mathrm{CC}$ tapes. It may seem surprising that materials with the highest and lowest CTE of selected powders listed in Table 1 contributed to the reduction in thermal expansion by the same level. The positive effect of filler with negative thermal expansion on thermal expansion modification is well known. For instance, in work of Tani et al. [8], the CTE of phenolic resin was decreased more than three times by addition of $52 \mathrm{vol} \%$ the $\mathrm{ZrW}_{2} \mathrm{O}_{8}$ fillers. We did not achieve such high reduction; this can be explained by the fact that our volumetric ratio of the powder was about $30 \%$ smaller. Besides volume amount, the particle size seems to be also important parameter as observed by Young et al. in [18]. Smaller particle size of the filler can contribute more to the CTE reduction, but much better effect can be achieved by mixing resin with filler which does not have homogeneous but various particle sizes. This can be attributed to the more uniform dispersion of filler particles in matrix. In our case, the best results were indeed achieved when powders with the highest particle size difference were used. Figure 4 shows images of particle distribution in resin matrix taken with a light microscope (LM) for three different systems. As evident here, the best distribution of the powder particles (a lot of tiny particles between the big ones that are not rounded) was achieved in the second sample with the $\mathrm{SiC}$ filler in the Stycast black resin. Therefore, the CTE reduction of this sample was comparable with the sample, where powder with the negative CTE and smaller particle size difference was used.

The presence of the glass transition is a double-edged issue. On the one hand, the $T_{\mathrm{g}}$ itself as endothermic event helps absorb produced heat in case of fault current limitation. On the other hand, the thermal expansion of resin in region above $T_{\mathrm{g}}$ increases significantly and it can cause cracking and delamination of thermal stabilization layer coated on CC. There is a question, how high is temperature which can be reached in the thermal stabilization layer 

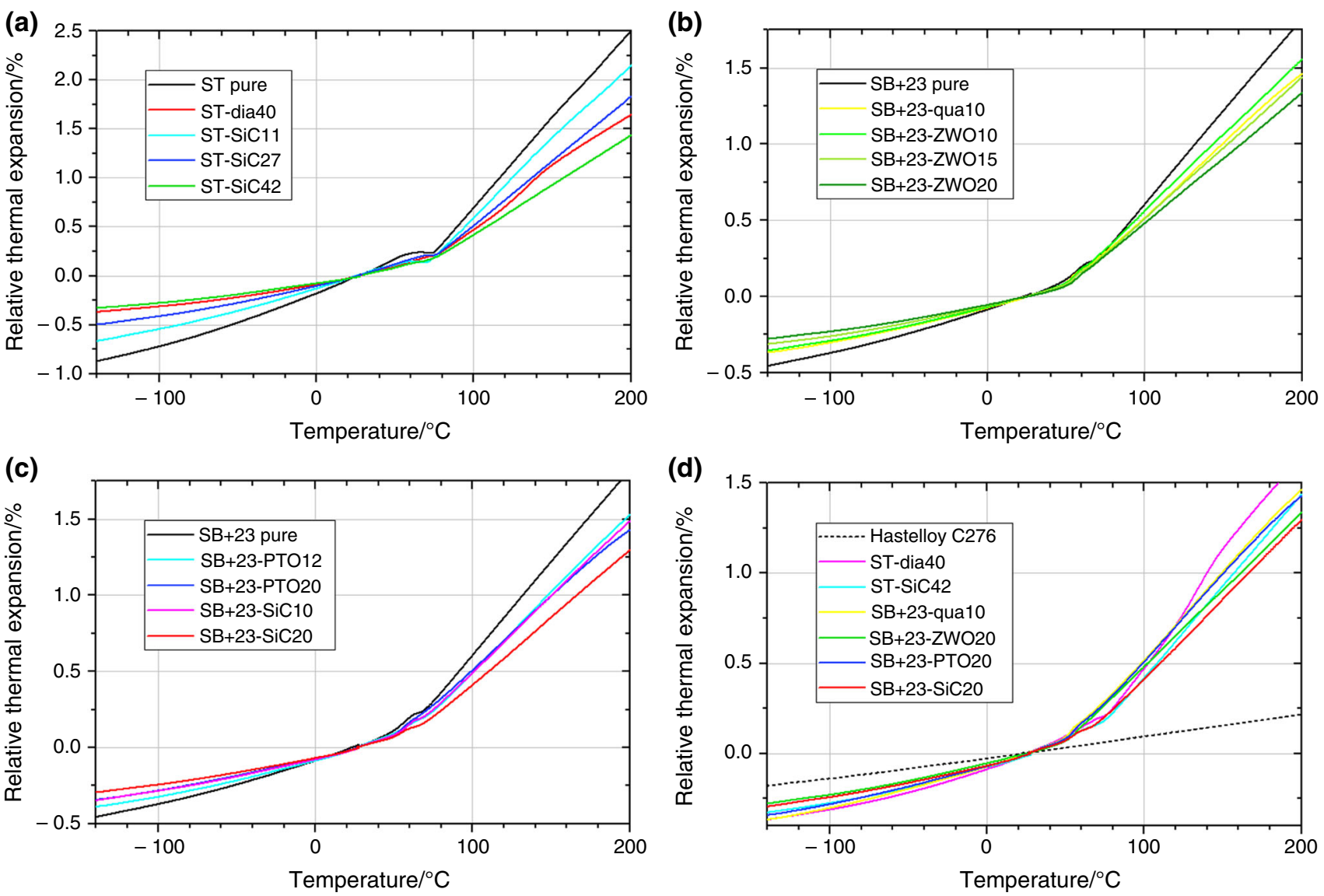

Fig. 3 Relative thermal expansion as a function of temperature for investigated systems: (a) Stycast transparent with $\mathrm{SiC}$ and diamond powders, (b, c) Stycast black with $\mathrm{SiO}_{2}, \mathrm{ZrW}_{2} \mathrm{O}_{8}, \mathrm{PbTiO}_{3}$ and $\mathrm{SiC}$

powders, (d) best achieved results from each system in one plot compared with Hastelloy $\mathrm{C} 276^{\circledR}$

Table 3 Densities, temperatures of glass transition, $T_{\mathrm{g}}$, and CTEs of investigated samples at room temperature and its average value in two temperature ranges before and after $T_{\mathrm{g}}$

\begin{tabular}{|c|c|c|c|c|}
\hline Sample & $\begin{array}{l}\text { Measured } \\
\text { density/g cm }\end{array}$ & $T_{\mathrm{g}} /{ }^{\circ} \mathrm{C}$ & $\begin{array}{l}\text { CTE at } \\
\mathrm{RT} / \times 10^{-6} \mathrm{~K}^{-1}\end{array}$ & $\begin{array}{l}\text { Average CTE below/ } / \\
\text { above } T_{\mathrm{g}} / \times 10^{-6} \mathrm{~K}^{-1}\end{array}$ \\
\hline ST & $1.172 \pm 0.002$ & 69.1 & 73 & $52 / 181$ \\
\hline ST-SiC11 & $1.364 \pm 0.002$ & 66.3 & 51 & $40 / 151$ \\
\hline ST-SiC27 & $1.658 \pm 0.002$ & 64.5 & 42 & $28 / 129$ \\
\hline ST-SiC42 & $1.873 \pm 0.004$ & 67.4 & 27 & $19 / 101$ \\
\hline ST-dia40 & $2.056 \pm 0.009$ & 65.7 & 32 & $21 / 116$ \\
\hline $\mathrm{SB}+23 \mathrm{LV}$ & $2.104 \pm 0.006$ & 67.1 & 38 & $28 / 122$ \\
\hline $\mathrm{SB}+23 \mathrm{LV}-\mathrm{SiC} 10$ & $2.183 \pm 0.009$ & 65.6 & 26 & $20 / 99$ \\
\hline $\mathrm{SB}+23 \mathrm{LV}-\mathrm{SiC} 20$ & $2.271 \pm 0.002$ & 66.9 & 24 & $17 / 88$ \\
\hline $\mathrm{SB}+23 \mathrm{LV}$-qua10 & $2.114 \pm 0.002$ & 61.1 & 29 & $22 / 94$ \\
\hline $\mathrm{SB}+23 \mathrm{LV}-\mathrm{PTO} 12$ & $2.531 \pm 0.008$ & 73.6 & 32 & $23 / 103$ \\
\hline SB + 23LV-PTO20 & $3.102 \pm 0.008$ & 85.9 & 27 & $20 / 92$ \\
\hline $\mathrm{SB}+23 \mathrm{LV}-\mathrm{ZWO} 10$ & $2.458 \pm 0.001$ & 63.9 & 29 & $21 / 100$ \\
\hline $\mathrm{SB}+23 \mathrm{LV}-\mathrm{ZWO} 15$ & $3.590 \pm 0.003$ & 66.7 & 27 & $19 / 93$ \\
\hline $\mathrm{SB}+23 \mathrm{LV}-\mathrm{ZWO} 20$ & $3.730 \pm 0.001$ & 63.5 & 24 & $17 / 85$ \\
\hline
\end{tabular}



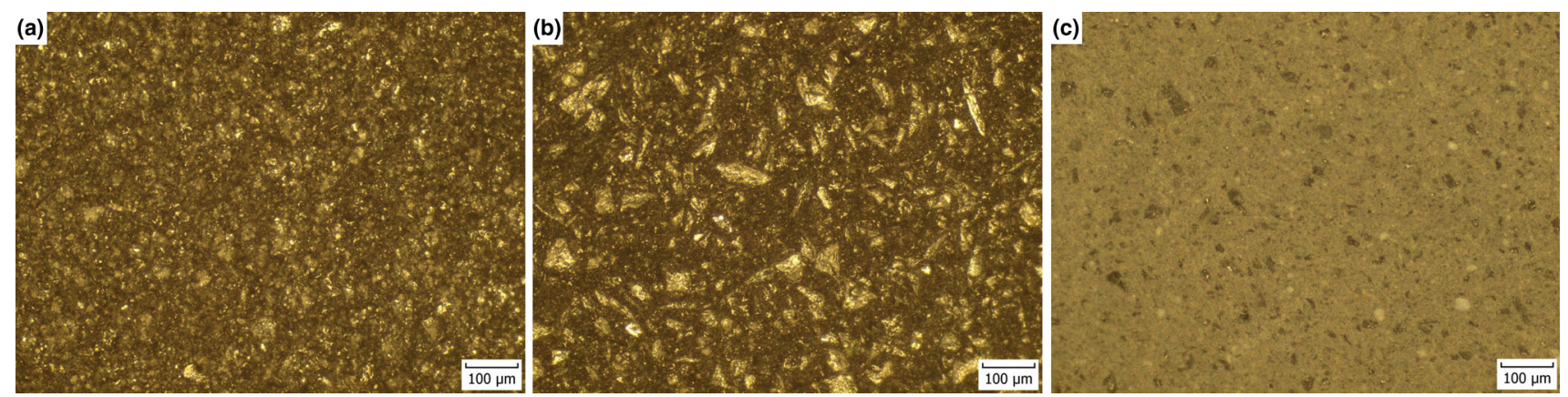

Fig. $4 \mathrm{LM}$ images of filler particles distribution in the composites (a) Stycast black with $20 \mathrm{vol} \% \mathrm{ZrW}_{2} \mathrm{O}_{8}$, (b) Stycast black with 20 vol\% SiC and (c) Stycast black with 20 vol\% $\mathrm{PbTiO}_{3}$

during limitation event lasting for $50 \mathrm{~ms}$. This is a subject of our further investigation.

\section{Heat capacity}

The aim of bringing an additional layer on the top of $\mathrm{CC}$ tape is to lead away and absorb the heat generated in $\mathrm{Ag}$ layer during limitation period. The heat absorption is more important in the first state of cooling process since the conduction of the heat through the interface $\mathrm{CC}$ tape/liquid nitrogen is very poor because of isolating bubble effect caused by too high temperature difference at the interface. Materials with high heat capacity can absorb a high amount of heat and increase their temperature only slightly. Magneto-thermal modelling of HTS tapes for resistive SCFCL in [19] showed that the key factor in success to attain readily the thermal stability is the heat capacity instead of thermal conductivity. Investigation of the influence of $c_{\mathrm{p}}$ and thermal conductivity on the temperature profile of a tape showed that even if an increase in the heat capacity reduces the thermal diffusivity, the increase in heat capacity has a positive effect on thermal stability. A high value of heat capacity is therefore desired in the additional layer. However, the mixing of high $c_{\mathrm{p}}$ materials with a component which has low $c_{\mathrm{p}}$ will decrease $c_{\mathrm{p}}$ of the entire composite. From this reason, we investigated the influence of used powders on $c_{\mathrm{p}}$ behaviour of composites.

Temperature dependences of heat capacity for investigated samples are depicted in Fig. 5a, b for the systems with Stycast transparent and Stycast black resin, respectively. As it can be seen there, the filler addition changes the $c_{\mathrm{p}}$ behaviour of composites in the aforementioned way. Further, very small shift of $T_{\mathrm{g}}$ was also observed. The $T_{\mathrm{g}}$ values were determined from $c_{\mathrm{p}}(T)$ plots, and they are listed in Table 3. The highest decrease in $c_{\mathrm{p}}$ in Stycast transparent resin system was due to $40 \mathrm{vol} \%$ of diamond addition (about $0.7 \mathrm{~J} \mathrm{~g}^{-1} \mathrm{~K}^{-1}$ at RT) and in Stycast black resin system due to $20 \mathrm{vol} \%$ of $\mathrm{PbTiO}_{3}$ filler (about $0.3 \mathrm{~J} \mathrm{~g}^{-1} \mathrm{~K}^{-1}$ at RT). According to measurements of thermal expansion, the samples with $\mathrm{SiC}$ and $\mathrm{ZrW}_{2} \mathrm{O}_{8}$ powder in Stycast black resin are the most interesting. In the $\mathrm{SB}+23 \mathrm{LV}-\mathrm{SiC} 20$ sample, the $c_{\mathrm{p}}$ value of $0.94 \mathrm{~J} \mathrm{~g}^{-1} \mathrm{~K}^{-1}$ was measured at RT which is decreased about $0.1 \mathrm{~J} \mathrm{~g}^{-1} \mathrm{~K}^{-1}$ in comparison with the pure Stycast black resin. In case of the SB $+23 \mathrm{LV}-Z$ WO20 sample, the decrease was slightly higher about $0.2 \mathrm{~J} \mathrm{~g}^{-1} \mathrm{~K}^{-1}$ at RT. Both decreases are, however, not dramatic, and the values of $c_{\mathrm{p}}$ remain for intended purpose still high enough.

\section{Thermal diffusivity and thermal conductivity}

Perfect thermal stabilization layer should consist of material with high heat capacity and simultaneously with high thermal conductivity. In comparison with metals and ceramics, polymers posse a higher heat capacity, but lower thermal conductivity because of relatively low atomic density. Nevertheless, such a deficiency could be improved by adding inorganic filler with high thermal conductivity in organic matrix. In this work obtained, thermal conductivity was calculated using measured values of heat capacity, density and thermal diffusivity. The measured densities of investigated samples are listed in Table 3 . The density of composites increases with higher content of filler. Figure 6 shows the variation in thermal diffusivity with the filler content depending on temperature separately for both Stycast resin systems. Similar plots with values of thermal conductivity are shown in Fig. 7. These results confirmed that the thermal diffusivity and thus thermal conductivity can be enhanced due to powder addition. The enhancement grew with the increase in filler content. In case of different particle sizes of filler, the smaller particles fill the gaps between the bigger particles. If the filler has sufficient amount in the resin matrix, the particles will touch each other and by this mean can create suitable conductive paths 
(a)

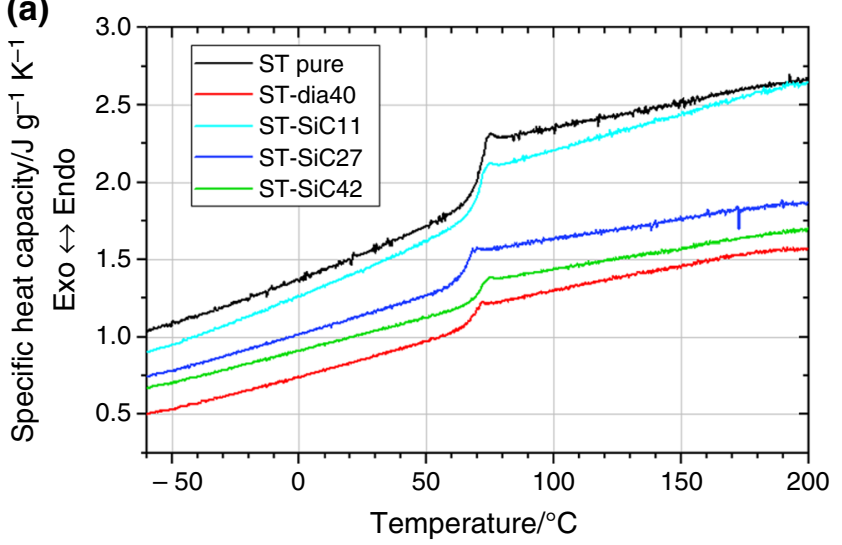

(b)

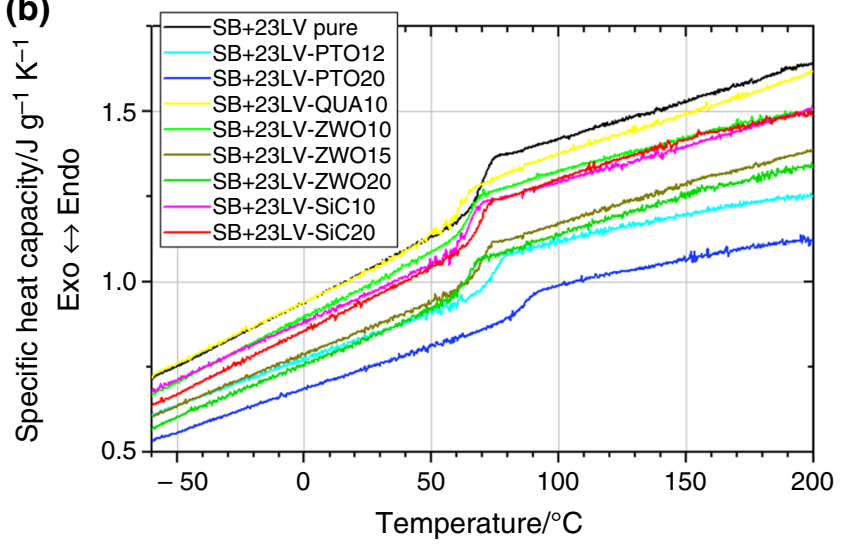

Fig. 5 Specific heat capacity as a function of temperature for investigated systems: (a) Stycast transparent with SiC and diamond powders, (b) Stycast black with $\mathrm{SiO}_{2}, \mathrm{ZrW}_{2} \mathrm{O}_{8}, \mathrm{PbTiO}_{3}$ and $\mathrm{SiC}$ powders
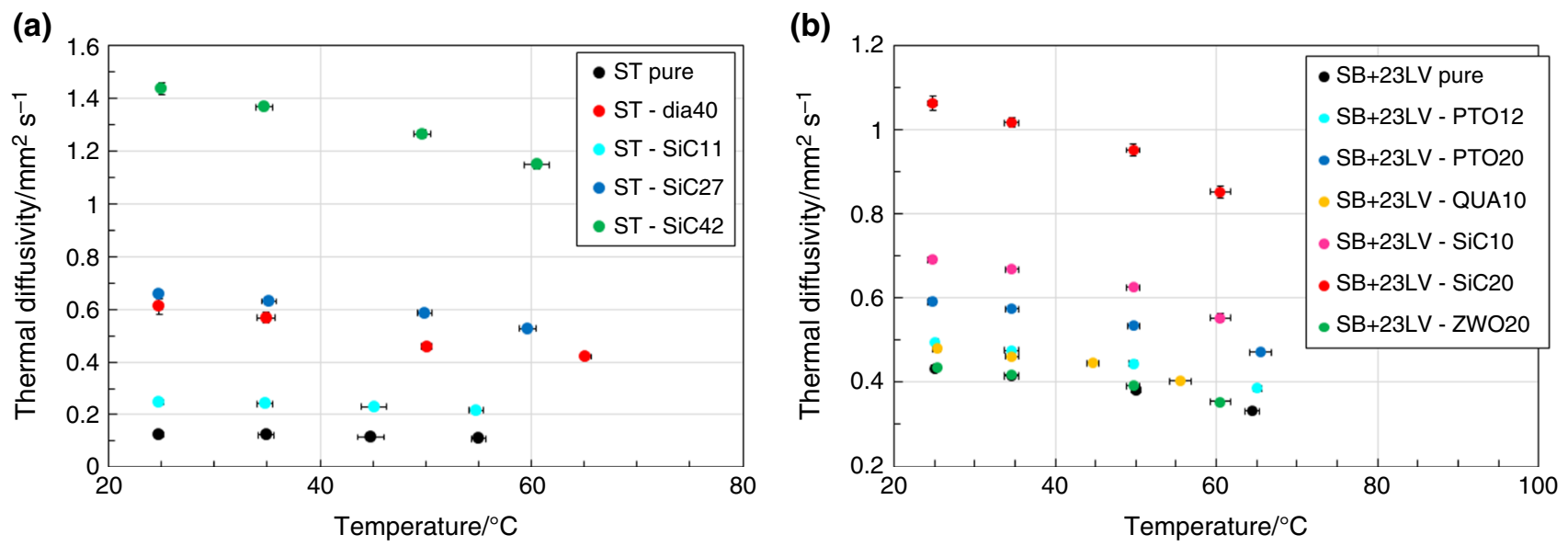

Fig. 6 Thermal diffusivity as a function of temperature for investigated systems: (a) Stycast transparent with SiC and diamond powders, (b) Stycast black with $\mathrm{SiO}_{2}, \mathrm{ZrW}_{2} \mathrm{O}_{8}, \mathrm{PbTiO}_{3}$ and $\mathrm{SiC}$ powders

(a)

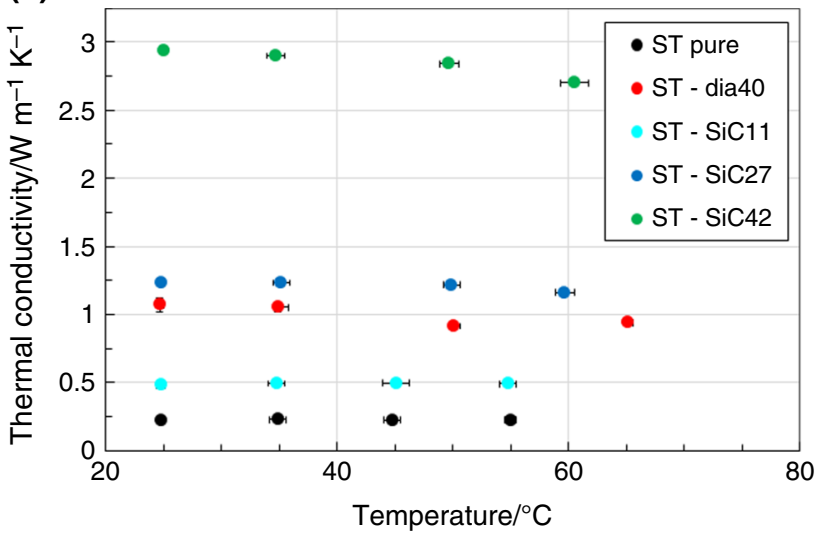

(b)

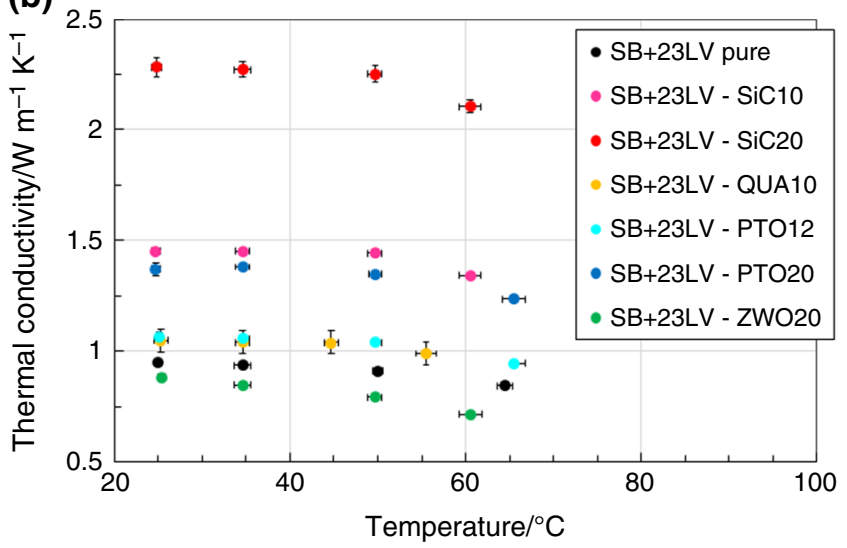

Fig. 7 Thermal conductivity as a function of temperature for investigated systems: (a) Stycast transparent with SiC and diamond powders, (b) Stycast black with $\mathrm{SiO}_{2}, \mathrm{ZrW}_{2} \mathrm{O}_{8}, \mathrm{PbTiO}_{3}$ and $\mathrm{SiC}$ powders

for heat flow as supposed in [20]. When the particles are not more isolated in non-conductive matrix, then it starts to be also important of which material the particles are, and filler with high thermal conductivity will increase much more the thermal conductivity of the composite than filler with low thermal conductivity. 

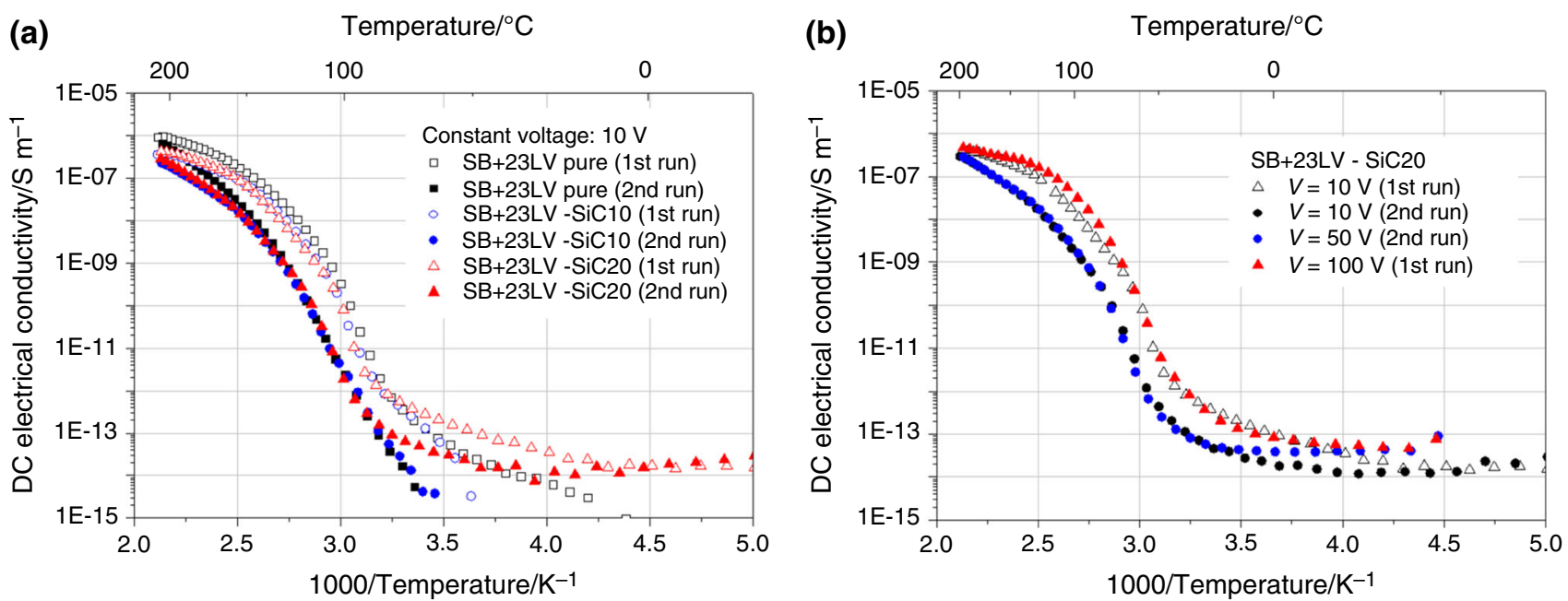

Fig. 8 DC electrical conductivity as a function of temperature for system Stycast black with SiC (a) measured in samples with different contents of filler, (b) measured in sample with $20 \% \mathrm{SiC}$ at different applied voltages

The sample $\mathrm{SB}+23 \mathrm{LV}$-qua10 contains a low volume of filler with low thermal conductivity; therefore, no significant influence on thermal conductivity was recorded. In the sample series with $\mathrm{ZrW}_{2} \mathrm{O}_{8}$ powder, the thermal conductivity was not affected because the filler has very similar thermal conductivity than used matrix. The $\mathrm{SiC}$ filler content with $40 \mathrm{vol} \%$ increased the conductivity of ST$\mathrm{SiC} 42$ composite more than 12 times. A comparable content of diamond filler in Stycast transparent resin did not show such improvement despite expected higher thermal conductivity. This can be caused particularly by high impurity of powder. Secondly, the diamond powder possesses particles with higher uniformity in their sizes than $\mathrm{SiC}$ and this could also contribute to smaller increase in thermal conductivity as expected. Similar effect of particle distribution can be seen for Stycast black system in Fig. 7b between samples with $\mathrm{SiC}$ and $\mathrm{PbTiO}_{3}$. The best value of $2.28 \mathrm{~W} \mathrm{~m}^{-1} \mathrm{~K}^{-1}$ at $\mathrm{RT}$ was achieved in the $\mathrm{SB}+23 \mathrm{LV}$ SiC20 sample which is nearly two and half times higher than in pure resin.

\section{Electrical conductivity}

The $\mathrm{SiC}$ material is a semiconductor with nonlinear electrical properties, and it can exhibit even metallic behaviour when it is sufficiently doped. Therefore, additional measurements of DC electrical conductivity, $\sigma_{\mathrm{DC}}$, were performed on the samples with this composition. The influence of the filler content on the temperature dependence of electrical conductivity is shown in Fig. 8a. Almost all $\sigma_{\mathrm{DC}}$ measurements were repeated because the samples adsorbed humidity. With the second heating cycle was this effect eliminated. The results measured at constant voltage showed that the contribution of the $\mathrm{SiC}$ filler addition up to $20 \mathrm{vol} \%$ to the $\sigma_{\mathrm{DC}}$ is negligible. The $\sigma_{\mathrm{DC}}$ drop at higher temperatures recorded for the samples with filler in comparison with the pure resin sample is probably connected with porosity effect, which was observable in the samples after addition of powder.

An effect of increasing voltage on change of the $\sigma_{\mathrm{DC}}$ is also important issue for applications in the field of fault current limiters. Applied voltage up to $100 \mathrm{~V}$ does not have significant influence on the $\sigma_{\mathrm{DC}}$ of composite with the highest amount of filler as obvious in Fig. 8b. Note that this measurement was performed just on sample with adsorbed humidity, and it should be compared only with the measurement from first run with applied voltage of $10 \mathrm{~V}$.

According to these measurements, the values of DC electrical conductivity of composite Stycast black with $\mathrm{SiC}$ filler are significantly lower than the value given by mixing rule (considering the $\sigma_{\mathrm{DC}}$ of pure $\mathrm{SiC}$ in range from $10^{-1}$ to $10^{-3} \mathrm{~S} \mathrm{~m}^{-1}$ ). This indicates that the $\mathrm{SiC}$ particles are in polymeric matrix distributed without significant agglomeration and its concentration is still low to reach percolation threshold of electrical conductivity.

\section{Conclusions}

Thermo-physical properties of several material candidates suitable as a thermal stabilization layer of CC tapes for superconducting fault current limiters were investigated. These materials were prepared as composites containing powder particles in Stycast organic binder. Besides the high electrical resistivity, the high heat capacity and thermal expansion of composites comparable with the substrate of CC tape are important for such applications. The best results were achieved with the system Stycast 
black + catalyst $23 \mathrm{LV}$ containing $\mathrm{SiC}$ or $\mathrm{ZrW}_{2} \mathrm{O}_{8}$ powder of $20 \mathrm{vol} \%$. They possess the CTE $\left(24 \times 10^{-6} \mathrm{~K}^{-1}\right)$ in temperature range from $-140{ }^{\circ} \mathrm{C}$ to $T_{\mathrm{g}}$ near the CTE of Hastelloy $\mathrm{C} 276^{\circledR}$, and it can prevent the delamination of coated layer. In terms of thermal conductivity, only the addition of $\mathrm{SiC}$ powder into resin improved approximately two and half times the thermal conductivity of composites without significant increase in electrical conductivity. On the other side, the heat capacity was for this system slightly decreased to the value of $1 \mathrm{~J} \mathrm{~g}^{-1} \mathrm{~K}^{-1}$ at RT, which is still high enough for the purpose of heat sinking.

Acknowledgements This work was supported in part by the European Union's Horizon 2020 research and innovative programme under Grant Agreement No. 721019 and by the Grant Agency of the Ministry of Education of the Slovak Republic and the Slovak Academy of Sciences (VEGA) under Contract No. 1/0151/17 and No. 1/0235/18.

Open Access This article is distributed under the terms of the Creative Commons Attribution 4.0 International License (http://creative commons.org/licenses/by/4.0/), which permits unrestricted use, distribution, and reproduction in any medium, provided you give appropriate credit to the original author(s) and the source, provide a link to the Creative Commons license, and indicate if changes were made.

\section{References}

1. Majka M, Kozak J, Kozak S. HTS tapes selection for superconducting current limiters. IEEE Trans Appl Supercond. 2007;27:5601405.

2. Noe M, Steurer M. High-temperature superconductor fault current limiters: concepts, applications, and development status. Supercond Sci Technol. 2007;20:R15.

3. Elschner S, Kudymow A, Brand J, Fink S, Goldacker W, Grilli F, Noe M, Vojenciak M, Hobl A, Bludau M, Jänke C, Krämer S, Bock J. ENSYSTROB-design, manufacturing and test of a 3-phase resistive fault current limiter based on coated conductors for medium voltage application. Physica C. 2012;482:98-104.

4. http://fastgrid-h2020.eu. Accessed 25 Sep 2018.

5. Shin HJ, Kim KL, Choi YH, Kwon OJ, Hahn S, Iwasa Y, Lee HG. Effects of impregnating materials on thermal and electrical stabilities of the HTS racetrack pancake coils without turn-turn insulation. IEEE Trans Appl Supercond. 2013;23:7700404.

6. Hu D, Ainslie MD, Rush JP, Durrell JH, Zou J, Raine MJ, Hampshire DP. DC characterization and 3D modeling of a triangular, epoxy-impregnated high temperature superconducting coil. Supercond Sci Technol. 2015;28:065011.

7. Yanagisawa Y, Sato K, Piao R, Nakagome H, Takematsu T, Takao T, Kamibayashi H, Takahashi M, Maeda H. Removal of degradation of the performance of an epoxy impregnated YBCO coated conductor double pancake coil by using a polyimideelectrodeposited YBCO-coated conductor. Physica C. 2012;476:19-22.

8. Tani J, Kimura H, Hirota K, Kido H. Thermal expansion and mechanical properties of phenolic resin $/ \mathrm{ZrW}_{2} \mathrm{O}_{8}$ composites. J Appl Polym Sci. 2007;106:3343-7.

9. Sheng J, Wang LD, Li D, Cao WP, Feng Y, Wang M, Yang ZY, Zhao Y, Fei WD. Thermal expansion behavior of copper matrix composite containing negative thermal expansion $\mathrm{PbTiO}_{3}$ particles. Mater Des. 2017;132:442-7.

10. Buysser K, Lommens P, Meyer C, Bruneel E, Hoste S, Driessche I. $\mathrm{ZrO}_{2}-\mathrm{ZrW}_{2} \mathrm{O}_{2}$ composites with tailor-made thermal expansion. Ceram Silik. 2004;48:139-44.

11. Barth C, Bagrets N, Weiss KP, Bayer CM, Bast T. Degradation free epoxy impregnation of REBCO coils and cables. Supercond Sci Technol. 2013;26:055007.

12. Sun L, Sneller A, Kwon P. $\mathrm{ZrW}_{2} \mathrm{O}_{8}$-containing composites with near-zero coefficient of thermal expansion fabricated by various methods: comparison and optimization. Compos Sci Technol. 2008;68:3425-30.

13. www.heraeus.com. Accessed 2 Sep 2018.

14. Chung DDL. Material for thermal conduction. Appl Therm Eng. 2001;21:1593-605.

15. Chen J, Xing X, Sun C, Hu P, Yu R, Wang X, Li L. Zero thermal expansion in $\mathrm{PbTiO}_{3}$-based perovskites. J Am Chem Soc. 2008;130:1144-5.

16. Tachibana M, Kolodiazhnyi T, Takayama-Muromachi E. Thermal conductivity of perovskite ferroelectrics. Appl Phys Lett. 2008;93:092902.

17. Kennedy CA, White MA. Unusual thermal conductivity of the negative thermal expansion material, $\mathrm{ZrW}_{2} \mathrm{O}_{8}$. Solid State Commun. 2005;134:271-6.

18. Young $\mathrm{KC}$, Liem H. Enhanced thermal conductivity of boron nitride epoxy-matrix composite through multi-modal particle size mixing. J Appl Polym Sci. 2007;106:3587-91.

19. Roy F, Dutoit B, Grilli F, Sirois F. Magneto-thermal modelling of second-generation HTS for resistive fault current limiter design purposes. IEEE Trans Appl Supercond. 2008;18:29-35.

20. Shen D, Zhan Z, Liu Z, Cao Y, Zhou L, Liu Y, Dai W, Nishimura $\mathrm{K}, \mathrm{Li}$ C, Lin CT, Jiang N, Yu J. Enhanced thermal conductivity of epoxy composites filled with silicon carbide nanowires. Sci Rep. 2017;7:2606.

Publisher's Note Springer Nature remains neutral with regard to jurisdictional claims in published maps and institutional affiliations. 